\title{
Evaluation of the Subjective Effect of Middle Ear Implantation in Hearing-Impaired Patients with Severe External Otitis
}

\author{
Ad F.M. Snik* \\ Noortje T.L. van Duijnhoven* \\ Jef J.S. Mulder* \\ Cor W.R.J. Cremers*
}

\begin{abstract}
The subjective benefit of middle ear implantation was studied in a group of 23 hearing-impaired patients who could not use conventional hearing aids owing to severe chronic external otitis. Changes in hearing disability (Abbreviated Profile of Hearing Aid Benefit [APHAB]) and changes in quality of life (Glasgow Benefit Inventory [GBI]) were determined. Mean benefit value on the APHAB for the subscale Ease of Communication was close to the mean reference value for conventional hearing aids. For the subscales Reverberation and Background Noise, a poorer result was found. Individual analysis of the APHAB scores showed significant benefit in 12 out of the 23 patients. According to the GBI, 16 out of 17 patients reported that middle ear implantation had made a positive impact on their quality of life. It is concluded that middle ear implantation has a positive effect on hearing difficulties and quality of life in hearing-impaired subjects who cannot use conventional devices. The APHAB outcomes were not better than those reported for conventional devices.
\end{abstract}

Key Words: APHAB, Glasgow Benefit Inventory, Otologics MET, selfassessment scales, Vibrant Soundbridge

Abbreviations: $\mathrm{APHAB}=$ Abbreviated Profile of Hearing Aid Benefit; $\mathrm{AV}=$ Aversiveness of sounds (subscale APHAB); BN = Background Noise (subscale $\mathrm{APHAB}$ ); $\mathrm{EC}=$ Ease of Communication (subscale APHAB); GBI = Glasgow Benefit Inventory; $\mathrm{PHAB}=$ Profile of Hearing Aid Benefit; RV = Reverberation (subscale APHAB)

\begin{abstract}
Sumario
Se estudió el beneficio subjetivo de la implantación del oído medio en un grupo de 23 pacientes hipoacúsicos que no podían utilizar auxiliares auditivos convencionales debido a una otitis externa crónica severa. Se determinaron los cambios en discapacidad auditiva (Perfil Abreviado del Beneficio del Auxiliar Auditivo [APHAB]) y los cambios en la calidad de vida (Inventario Glasgow de Beneficio [GBI]). El valor medio de beneficio en el APHAB para la sub-escala Facilidad de Comunicación fue cercano al valor medio de referencia para los auxiliares auditivos convencionales. Para las sub-escalas de Reverberación y Ruido de Fondo, se encontró un resultado más pobre. EI análisis individual de los puntajes APHAB mostró un beneficio significativo en 12 de los 23 pacientes. De acuerdo con el GBI, 16 de los 17 pacientes reportaron que la implantación del oído medio había tenido un impacto positivo en la calidad de sus vidas. Se concluye que la implantación del oído medio
\end{abstract}

*Department of Otorhinolaryngology, Radboud University Nijmegen Medical Centre, The Netherlands

Ad F.M. Snik, PhD, Department of Otorhinolaryngology, Radboud University Nijmegen Medical Centre, PO Box 9101, 6500 HB Nijmegen, The Netherlands; Phone: +31-243614927; Fax: +31-243540251; E-mail: a.snik@kno.umcn.nl 
tiene un efecto positivo sobre las dificultades de comunicación y sobre la calidad de vida en sujetos hipoacúsicos que no pueden utilizar dispositivos convencionales. Los resultados del APHAB no fueron mejores que aquellos reportados con dispositivos convencionales.

Palabras Clave: APHAB, Inventario Glasgow de Beneficio, Otologics MET, escalas de auto-evaluación, Vibrant Soundbridge

Abreviaturas: APHAB = Perfil Abreviado de Beneficio del Auxiliar Auditivo; $\mathrm{AV}=$ Aversión al sonido (sub-escala $\mathrm{APHAB}$ ); $\mathrm{BN}=$ ruido de fondo (subescala $A P H A B$ ); $E C$ = facilidad de comunicación (sub-escala APHAB); $\mathrm{GBI}=$ Inventario Glasgow de Beneficio; PHAB = Perfil de Beneficio del Auxiliar Auditivo; RV = reverberación (sub-escala APHAB)

$\mathrm{O}$ ver the past decade, middle ear implants have been used as an alternative treatment for patients with moderate to severe sensorineural hearing loss. At present, two different types of middle ear implant are commercially available, the Vibrant Soundbridge (Ball et al, 1997; Snik and Cremers, 2001; Luetje et al, 2002; Sterkers et al, 2003) and the Otologics MET device (Kasic and Fredrickson 2001; Jenkins et al, 2004). To describe and evaluate the effect of middle ear implantation, frequent use is made of audiometric variables, such as soundfield thresholds and speech-recognition scores. Self-assessment scales can also be used to gain more insight into the subjective effect of implantation. The most commonly used questionnaire for this purpose is the standardized Abbreviated Profile of Hearing Aid Benefit (APHAB). Developed from the Profile of Hearing Aid Performance (PHAP) combined with the Profile of Hearing Aid Benefit (PHAB), the APHAB quantifies personal hearing difficulties in various everyday listening situations (Cox and Alexander, 1995). This questionnaire assesses primarily hearing disability not hearing handicap. The questionnaire comprises four subscales, three of which address speech understanding in different situations, while the fourth subscale inquires about negative reactions to environmental sounds. Cox et al (1991) and Cox and Rivera (1992) reported that the original standardized PHAB had good test-retest reliability and sensitivity. Administration of the APHAB before and after hearing aid fitting proved to be a valuable and sensitive method to detect the benefit of the intervention (Almeida and Taguchi, 2004).
The (A)PHAB has been used as a subjective assessment scale in several studies on middle ear implantation (Fraysse et al, 2001; Lenarz et al, 2001; Luetje et al, 2002; Todt et al, 2002; Uziel et al, 2003; Jenkins et al, 2004). Comparisons were made between APHAB scores obtained before implantation, while the patient was still using his conventional hearing aids, and those obtained after implantation. In general, positive and significant changes have been reported, which indicates that implanted patients experience improvements compared to their conventional hearing aid. However, it should be noted that, at some stage, these patients chose an invasive treatment and might feel committed; this might bias the outcomes.

Cox and Alexander (1995) reported reference APHAB scores, obtained in a group of patients with moderate to severe hearing loss. These reference values will be used for comparisons although they are based on research in patients fitted with conventional linear hearing aids.

In addition, the Glasgow Benefit Inventory (GBI) was used. The GBI assesses changes in quality of life after otological treatment (Robinson et al, 1996). Whereas the APHAB concentrates on hearing disabilities, the GBI focuses on general feelings of well-being such as self-confidence, self-esteem, happiness, and physical health. Such target areas are important to gain broad insight into the subjective effects of the otological treatment. While APHAB has been used frequently in studies on the effect of middle ear implantation, the GBI has only been used in one study on the Vibrant Soundbridge (Sterkers et al, 2003).

Audiometric results of the middle ear 
implant recipients at the University Medical Centre St Radboud in Nijmegen have been published previously (Snik and Cremers 2001; Snik et al, 2001; Snik et al, 2004), but there was no mention of subjective self-assessments. The aim of the present study was to evaluate the subjective effect of middle ear implantation with the APHAB and GBI questionnaires in a unique study group; our group only comprised hearing-impaired patients with chronic external otitis who were therefore unable to wear conventional hearing aids successfully. In contrast, the patients included in the cited studies (Fraysse et al, 2001; Lenarz et al, 2001; Luetje et al, 2002; Todt et al, 2002; Jenkins et al, 2004) included mainly dissatisfied conventional hearing aid users.

The study was not aimed at a comparison between the two middle ear implant systems because of selection bias, as the Otologics MET device is more powerful than the Vibrant Soundbridge (Snik et al, 2004), but on the other hand, the Vibrant Soundbridge is easier to implant. Therefore, the Otologics MET was only applied in patients with more severe hearing loss.

\section{MATERIALS AND METHODS}

\section{Study Design}

This clinical study had a prospective single subject (repeated) measures design, in which each patient served as his or her own control subject. Early in the selection phase, all the patients filled out the APHAB questionnaire (baseline measurement). The APHAB questionnaire was readministered to the patients six and twelve months after audioprocessor fitting, while the GBI questionnaire was only filled out once, after twelve months of middle ear implant use. In addition to the longitudinal evaluation, the APHAB scores obtained after implantation were compared to published reference scores, obtained in a large group of patients using conventional hearing aids (Cox and Alexander, 1995).

To assess whether audioprocessor fitting was adequate, realizing that these devices make use of nonlinear amplification, speech gain was measured and compared to target gain values obtained with the well-validated NAL rule (Dillon, 2001).
Speech gain was defined as the shift between the unaided and aided speech audiograms (speech recognition-intensity graphs) at $65 \mathrm{~dB}$ input, as introduced previously (Snik and Cremers, 2001). Mean NAL target gain values at frequencies of $0.5,1$, and $2 \mathrm{kHz}$ for an input level of $65 \mathrm{~dB}$ were used to compare with measured gain.

\section{Study Population}

The study population comprised 23 patients, 11 men and 12 women, aged 53.0 $\pm 14.5 \mathrm{yr}$ (range 18-79 yr) at the time of implantation. All the patients had symmetrical sensorineural hearing loss and chronic, therapy-resistant external otitis. Fourteen patients received the Vibrant Soundbridge (with the 404 audioprocessor; Med-El, Innsbruck, Austria), and nine patients received the Otologics MET (with the standard button processor; LLC, Boulder, CO) according to the severity of their hearing loss. The mean hearing loss for the Vibrant Soundbridge users was 49 $\pm 8 \mathrm{~dB}$ HL (range 32-57 dB HL) and for the Otologics MET users was $64 \pm 11 \mathrm{~dB}$ HL (range 50-77 dB HL). Six weeks after implant surgery, the audioprocessor was fitted in a nonlinear amplification mode according to the wishes of the patient. If necessary, adjustments were made during follow-up visits.

Before implantation, all the patients used conventional hearing aids. Special ear moulds had been applied, vented if possible and made of allergy-free material or silver coated. A total of 13 patients had decided to stop using their conventional hearing aid at some stage due to deterioration of their chronic otitis. The others used their hearing aids daily as long as they could stand them.

Data on one more patient were excluded, because he had hereditary diabetes that led to sudden symmetrical hearing deterioration a few months after implantation, and his final hearing thresholds were poorer than those permitted for middle ear implantation.

\section{Self-Assessment Scales}

\section{APHAB Questionnaire}

The APHAB is a standardized prospective questionnaire that quantifies personal 
hearing difficulties in various everyday listening situations (Cox and Alexander, 1995) with subscales Ease of Communication (EC), Reverberation (RV), and Background Noise (BN). Aversiveness of sounds (AV), the fourth subscale, measures negative reactions to environmental sounds. The results of each subscale are given as percentages of difficulty with listening in that specific situation. Cox and Alexander (1995) reported aided and unaided reference scores, obtained in a group of 128 patients with moderate to severe hearing loss, fitted with conventional linear hearing aids. These scores will be referred to as the "APHAB reference data" and used in the present study for comparisons. It should be noted that a minority of the patients studied by Cox and Alexander were fitted binaurally (viz. $42 \%$ ).

\section{GBI Questionnaire}

The GBI is a retrospective standardized questionnaire that examines the impact of an otological treatment such as middle ear implantation on the health status of the patient. "Health status" is defined as the general perception of well-being, including total psychological (general), social, and physical well-being (Robinson et al, 1996). Scores range from -100 to +100 , which corresponds with profound deterioration to great improvement in quality of life.

\section{Analysis}

Analyses were performed on the latest data available, that is, either twelve months $(\mathrm{n}=14)$ or six months $(\mathrm{n}=9)$ after implantation. APHAB data were available from all 23 patients, while GBI data were available from 17 patients. Six patients did not fill in the 12-month questionnaires (neither the APHAB nor the GBI): two of them because of severe illness not related to the implantation, one other patient because of a device failure, and the three others for unknown reasons. Furthermore, three patients returned only the GBI questionnaire.

Differences in scores between baseline and middle ear implantation were analyzed using paired T-tests and Wilcoxon tests for normally distributed variables and notnormally distributed variables, respective- ly. Data are expressed as mean values \pm standard deviations. Differences between baseline and middle ear implantation are expressed as mean with their 95\% confidence interval. If $p<0.05$ then the differences are considered statistically significant. Analysis of variance was used to investigate the possible influence of the type of middle ear implant. SPSS 12.0 statistical software was used for all calculations.

Individual differences in APHAB scores were checked for significance using the guidelines formulated by Cox and Alexander (1995). The 95\% critical difference on the APHAB subscales EC, RV, and $\mathrm{BN}$ was $26 \%$. The $95 \%$ critical difference on the subscale AV was $21 \%$ when no conventional hearing aid had been used at baseline, versus $36 \%$ when a hearing aid had been used. In the joint evaluation of the APHAB subscales EC, RV, and BN, a difference of $10 \%$ or more for each subscale was considered to be significant $(\mathrm{p}<0.02)$.

\section{RESULTS}

\section{Fitting Audioprocessors}

The average difference between the measured gain and target gain calculated with the NAL rule was $2.3 \pm 6.4 \mathrm{~dB}$ (range -11.5 to $7.6 \mathrm{~dB}$ ). This indicated that on the average the audioprocessor fitting was adequate. The mean aided phoneme score at a presentation level of $65 \mathrm{~dB}$ SPL was $83 \%$ $\pm 13 \%$ (range: $55 \%$ to $95 \%$ ). Five of the patients continued to use their conventional device in the contralateral ear, especially during demanding listening situations.

\section{Self-Assessment Scales}

\section{APHAB Questionnaire}

Figure 1 presents the mean APHAB scores and SD as obtained before implantation and at 6 and 12 months after fitting of the device. Only the scores from the 14 patients with a complete set of questionnaire data were used. The figure shows that there is an obvious improvement in the $\mathrm{EC}, \mathrm{BN}$, and RV scores after device fitting and that these changes are rather stable 
APHAB scores over time

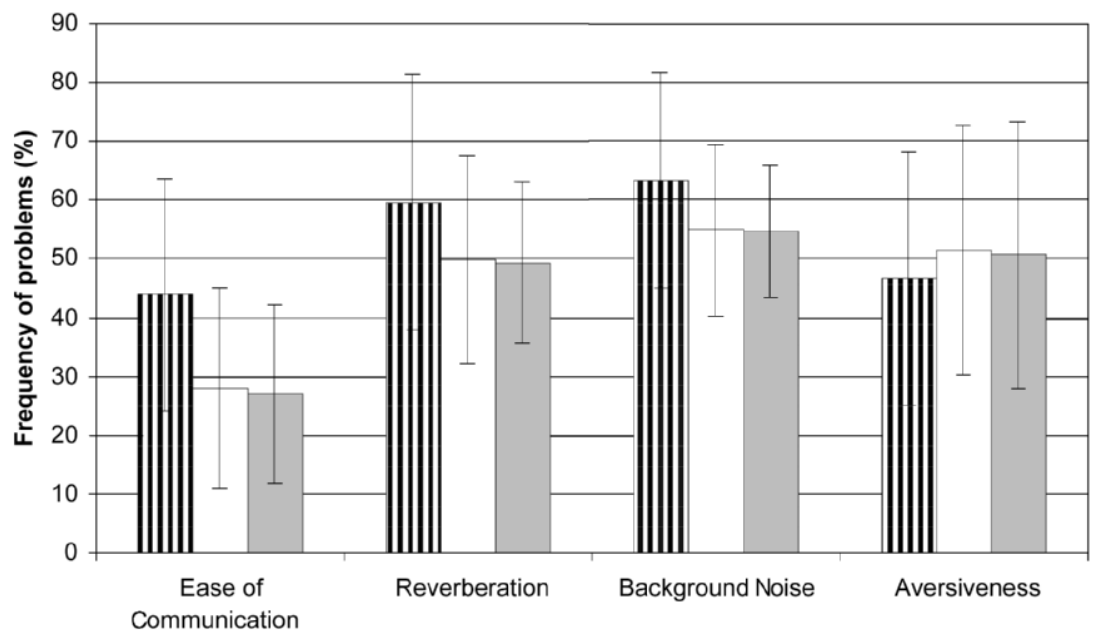

Figure 1. Mean $A P H A B$ scores per category, obtained before implantation (first bars) and 6 months (middle bars) and 12 months (last bars) follow-up, for the subgroup of 14 patients with a complete data set. Standard deviations are indicated.

over time. It was decided that the 12-month data would be used for further statistical analysis supplemented with the 6-month data for the remaining nine patients.

Table 1 shows the results of the four APHAB subscales at baseline and after middle ear implantation. Scores on the subscales EC, RV, and BN were significantly lower after middle ear implantation than at baseline $(\mathrm{p}<0.001, \mathrm{p}=0.02$ and 0.03 , respectively), whereas $\mathrm{AV}$ scores were higher after middle ear implantation than at baseline, but this difference was not significant $(\mathrm{p}=0.62)$.

Results of the individual analysis according to the guidelines formulated by Cox and Alexander (1995) are given in Table 2. This table shows that in several patients there was significant improvement in APHAB scores between baseline and middle ear implantation. The number of patients with a significant deterioration is also listed. Altogether, in 12 out of the 23 patients (52\%) a significant improvement was found on one of the APHAB subscales or on the combined subscales. Figure 2 shows the mean scores on the APHAB subscales in the present study compared with the reference values reported by $\mathrm{Cox}$ and Alexander (1995).

Benefit scores (difference between baseline and postintervention values) on the four subscales were comparable between the patients with the Vibrant Soundbridge and those with the Otologics MET; statistically significant differences were not present $(p=0.86$ to 1.00$)$.

Table 1. Average APHAB Scores (\%)

\begin{tabular}{lcrrc} 
APHAB subscale & $\begin{array}{c}\text { Baseline } \\
\text { Mean } \pm \text { SD }\end{array}$ & $\begin{array}{c}\text { MEI } \\
\text { Mean } \pm \text { SD }\end{array}$ & $\begin{array}{r}\text { MEI; baseline } \\
\text { Mean (95\% CI) }\end{array}$ & p-value* \\
\hline Ease of Communication & $48.8 \pm 20.8$ & $29.2 \pm 17.3$ & $19.6(9.0-30.1)$ & $<0.001$ \\
Reverberation & $67.9 \pm 21.3$ & $55.2 \pm 18.7$ & $12.7(2.6-22.9)$ & 0.02 \\
Background Noise & $65.8 \pm 18.6$ & $56.5 \pm 11.6$ & $9.2(1.3-17.2)$ & 0.03 \\
Aversiveness & $37.1 \pm 25.1$ & $39.6 \pm 24.6$ & $-2.5(-12.7-7.7)$ & 0.62 \\
\hline
\end{tabular}

Note: $\mathrm{n}=23$.

${ }^{*} p<0.05$ was considered statistically significant

Table 2. Number of Patients with Significant Differences in APHAB Scores

\begin{tabular}{lcc} 
APHAB subscale & $\begin{array}{c}\text { \# significant benefit } \\
\text { implantation-baseline }\end{array}$ & $\begin{array}{c}\text { \# significant deterioration } \\
\text { implantation-baseline }\end{array}$ \\
\hline Ease of Communication & 10 & 0 \\
Reverberation & 9 & 1 \\
Background Noise & 6 & 0 \\
Aversiveness & 1 & 1 \\
Subscales jointly (EC, RV, and BN) & 8 & 1 \\
\hline
\end{tabular}




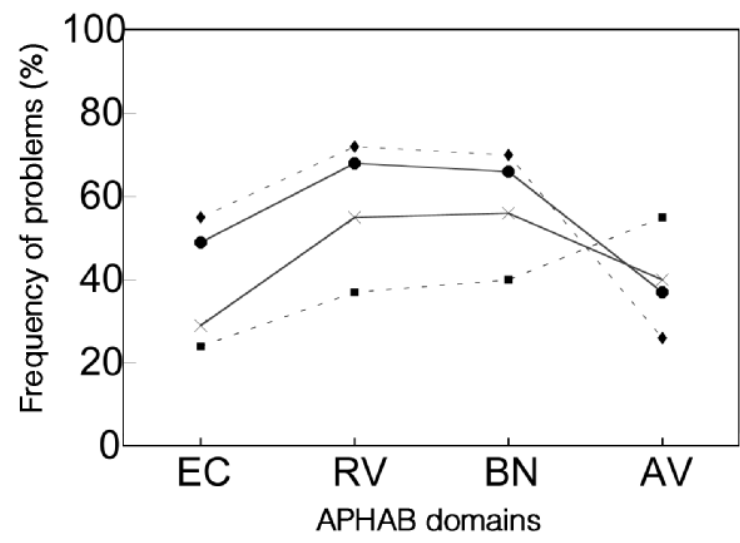

- pre-impl * post-impl • Cox unaided - Cox aided

Figure 2. Mean APHAB scores obtained before implantation ("pre-impl") and after implantation ("post-impl"). For reference purposes, unaided and aided mean scores are added as reported by Cox and Alexander (1995; "Cox unaided," "Cox aided"). EC = Ease of Communication, $\mathrm{RV}=$ (speech recognition in) Reverberation; $\mathrm{BN}=$ (speech recognition in) Background Noise, $\mathrm{AV}=$ Aversiveness (of sounds).

\section{GBI Questionnaire}

Table 3 shows the GBI results on the three subscales and the overall score, 12 months after middle ear implantation. Scores on the GBI were comparable for patients with the Vibrant Soundbridge and those with the Otologics MET ( $p=0.19$ to 0.51 ).

\section{DISCUSSION}

$\mathrm{T}_{\mathrm{i}}$ The present prospective study on hearing-impaired patients with severe external otitis addressed the subjective effect of middle ear implantation on hearing difficulties and quality of life. To obtain data, we used the APHAB and GBI questionnaires. First of all, it was studied whether or not the amplification (gain) of the middle ear implants was adequate. On the average, the difference between measured gain and the NAL target gain was negligible; however, there was spread in the data. To obtain additional evidence con- cerning the appropriateness of the fittings, Pearson correlation coefficients were calculated between the individual differences between NAL target gain and measured gain on the one hand and individual APHAB benefit scores on the other. Nonsignificant correlations were found (Pearson's rho between 0.02 and -0.11). Therefore, it is concluded that the quality of device fitting in terms of gain was adequate.

\section{APHAB Scores}

Table 1 and Figure 2 show that, as expected, our patients experienced significantly fewer problems in the domains EC, $\mathrm{RV}$, and $\mathrm{BN}$ of the APHAB after implantation than at baseline. In contrast the subscale AV showed small but nonsignificant deterioration. Figure 2 also shows that the APHAB scores of our patients after implantation are less favorable than the aided APHAB reference data, except for EC.

In comparison with other studies on middle ear implants (Fraysse et al, 2001; Lenarz et al, 2001; Luetje et al, 2002; Todt et al, 2002; Uziel et al, 2003; Jenkins et al, 2004), our postimplantation scores are poorer. Typically, mean literature scores are in between the present scores and the aided APHAB reference scores. At least two factors might have played a role. All our subjects had external otitis and were therefore unable to wear conventional hearing aids successfully. Thus, middle ear implantation had been performed on a medical indication. In all the other studies, at least a proportion of the population had received a middle ear implant on nonmedical grounds. Examples of these reasons were physical discomfort, dissatisfaction with sound quality, and acoustic feedback (Fraysse et al, 2001; Lenarz et al, 2001; Luetje et al, 2002; Todt et al, 2002; Jenkins et al, 2004) as well as cosmetic complaints (Uziel et al, 2003).

Table 3. Average GBI Scores

\begin{tabular}{lccccc} 
GBI subscale & p-value* & $\begin{array}{c}\text { Benefit score } \\
\text { Mean } \pm \text { SD }\end{array}$ & Positive & No change & Negative \\
\hline Average (overall) & $<0.001$ & $32.9 \pm 15.4$ & 94.1 & 5.9 & 0.0 \\
General & $<0.001$ & $41.5 \pm 15.2$ & 100.0 & 0.0 & 0.0 \\
Social & 0.008 & $17.6 \pm 23.9$ & 47.1 & 52.9 & 0.0 \\
Physical & 0.10 & $15.7 \pm 37.5$ & 35.3 & 41.2 & 23.5 \\
\hline
\end{tabular}

Note: $\mathrm{n}=17$.

${ }^{*} p<0.05$ was considered statistically significant 
It is conceivable that the subjective results of patients who dislike their conventional device are biased, which might explain the better APHAB scores reported in literature. Another variable that affects the reliability of questionnaire scores is the timing of the postoperative measurements. If the patients are evaluated too soon they will lack experience with the implant, and enthusiasm bias might be present owing to feelings of gratitude. We had a relatively long follow-up period, (substantially) longer than in the other studies. In summary, it is suggested that the present data are probably the most appropriate ones owing to less bias than generally found in the middle ear implant literature.

The poorer BN and RV scores that we found postimplantation might be ascribed to the unilateral application of the middle ear implant; $42 \%$ of the Cox and Alexander reference group (1995) used bilateral devices while in our study population this figure was $22 \%$ (five of our patients continued to use their conventional device in the contralateral ear; two of them permanently, the other three incidentally). Figure 3 shows our mean result as well as the individual result of the two patients who used a conventional device permanently in the contralateral ear. Little difference is seen. Lenarz et al (2001) also studied postim-

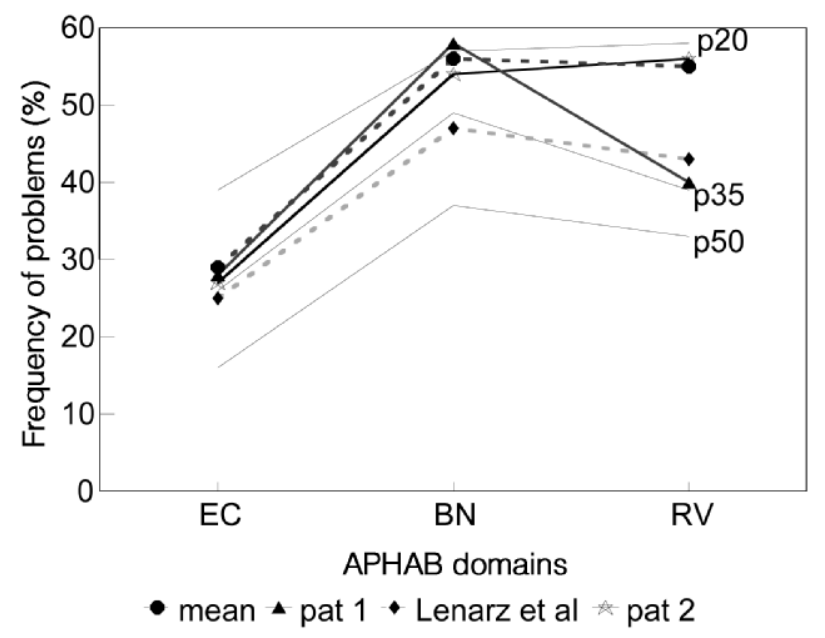

Figure 3. Mean postintervention APHAB scores for the whole group (mean) and individual data from the two patients who used a conventional device in their contralateral ear ("pat 1" "pat 2"). Furthermore, the mean scores reported by Lenarz et al (2001) are added and, for reference purposes, the 20th (p20), 35th (p35), and 50th (p50) percentile scores as reported by Cox and Alexander (1995). EC = Ease of Communication, $\mathrm{RV}=($ speech recognition in $)$ Reverberation; $\mathrm{BN}=($ speech recognition in) Background Noise. plantation APHAB scores. Twelve of their patients (35\%) consistently used a conventional hearing aid in their nonimplanted ear; the mean data of Lenarz et al are also plotted in Figure 3. This proportion of 35\% is close to the $42 \%$ of binaural hearing aid users in the APHAB reference group. At last, the 20th, 35th, and 50th percentile scores taken from that reference group are plotted (Cox and Alexander, 1995). As all the scores presented in Figure 3 are clearly below p50, it is suggested that the differences in APHAB scores between middle ear implant users and the APHAB norms cannot solely be ascribed to unilateral versus bilateral fittings. Therefore, probably, sound quality of the middle ear implants plays a part.

Analysis of the individual APHAB benefit scores according to the guidelines formulated by Cox and Alexander (1995) revealed significant benefit on the subscales EC and $\mathrm{RV}$ in about $40 \%$ of our patients and $25 \%$ for BN (see Table 2). When the subscales were analyzed jointly, $35 \%$ of the patients had fewer problems in communication than at baseline, versus $4 \%$ (one patient) who showed significant deterioration in communication. Altogether 52\% of our patients showed a significant improvement on one specific subscale or on the three subscales EC, RV, and BN combined. Such individual analyses were not performed in the previous studies, except by Fraysse et al (2001). They reported a significant benefit in $70 \%$ of their patients.

\section{GBI Results}

Table 3 presents the GBI scores. In the GBI, the social and physical subscales contain just three questions each; therefore, the discussion is focused on the overall score. In the literature, only Sterkers et al (2003) used the GBI to assess the change in quality of life after middle ear implantation. An overall GBI profit score of 17 was reported in their multicenter study, compared to our overall profit value of 33 . The fact that our patients had trouble wearing any conventional hearing aids might explain our relatively high mean GBI score. After all, after implantation our patients could hear well without pain and/or itching and therefore probably felt more comfortable in life. 
Six of our patients did not fill out the GBI. A comparison was made between the APHAB scores of these 6 patients compared to that of the rest of the group. No significant difference was found that suggests that the 17 subjects formed a representative subgroup.

The change in quality of life after middle ear implantation measured with the GBI was comparable to that after BAHA treatment (a semi-implantable bone-conduction device); GBI scores of 31 (Arunchalam et al, 2001) and 33 (McLarnon et al, 2004) were reported. Somewhat higher GBI scores were reported after cochlear implantation of 36 (Vermeire et al, 2005), 40 (Robinson et al, 1996), and 45 (UK Cochlear Implant Study Group, 2004).

This study demonstrated the positive subjective effects of middle ear implantation on hearing difficulties and quality of life in hearing-impaired patients with severe external otitis. Results of the APHAB indicated improvements in perceived hearing disability; however, this benefit was moderate in comparison with previous studies on middle ear implantation as well as in comparison with APHAB reference data. Thus, although the surplus value of middle ear implantation over conventional hearing aids was not shown, middle ear implantation was highly beneficial and appreciated; according to the GBI, our subjects, with severe external otitis, experienced great improvement in their quality of life.

\section{REFERENCES}

Almeida K de, Taguchi CK. (2004) The use of the selfassessment questionnaire to evaluate hearing aid benefit. Pro Fono 16:101-110.

Arunachalam PS, Kilby D, Meikle D, Davison T, Johnson IJM. (2001) Bone-anchored hearing aid quality of life assessed by Glasgow Benefit Inventory. Laryngoscope 111:1260-1263.

Ball G, Huber A, Goode RL. (1997) Scanning laser Doppler vibrometry of the middle ear ossicles. Ear Nose Throat J 76:213-218.

Cox RM, Alexander GC. (1995) The abbreviated profile of hearing aid benefit. Ear Hear 16:176-186.
Cox RM, Gilmore C, Alexander GC. (1991) Comparison of two questionnaires for patient-assessed hearing aid benefit. J Am Acad Audiol 2:134-145.

Cox RM, Rivera IM. (1992) Predictability and reliability of hearing aid benefit measured using the PHAB. $J$ Am Acad Audiol 3:242-254.

Dillon H. (2001) Hearing Aids. New York: Thieme Verlag.

Fraysse B, Lavieille J-P, Schmerber S, Enée V, Truy E, Vincent C, Vaneecloo FM, Sterkers O. (2001) A multicenter study of the Vibrant Soundbridge middle ear implant: early clinical results and experience. $\mathrm{Otol}$ Neurotol 22:952-961.

Jenkins HA, Niparko JK, Slattery WH, Neely JG, Fredrickson JM. (2004) Otologics middle ear transducer ${ }^{\mathrm{TM}}$ ossicular stimulator: performance results with varying degrees of sensorineural hearing loss. Acta Otolaryngol 124:391-394.

Kasic JF, Fredrickson JM. (2001) The Otologics MET ossicular stimulator. Otolaryngol Clin North Am 34:501-513.

Lenarz T, Weber BP, Issing PR, Gnadeberg D, Ambjornsen K, Mack KF, Winter M. (2001) Vibrant Soundbridge implant: a new hearing prosthesis for patients with sensorineural hearing loss. Part 2: audiological results. Laryngorhinootologie 80:370-380.

Luetje CM, Brackman D, Balkany TJ, Maw J, Baker RS, Kelsall D, Backous D, Miyamoto R, Pansier S, Arts A. (2002) Phase III clinical trial results with the Vibrant Soundbridge implantable middle ear hearing device: a prospective controlled multicenter study. Otolaryngol Head Neck Surg 126:97-107.

McLarnon CM, Davison T, Johnson IJM. (2004) Boneanchored hearing aid: comparison of benefit by patient subgroups. Laryngoscope 114:942-944.

Robinson K, Gatehouse S, Browning GC. (1996) Measuring benefit from otorhinolaryngological surgery and therapy. Ann Otol Rhinol Laryngol 105:415-422.

Snik AFM, Cremers CWRJ. (2001) Vibrant semiimplantable hearing device with digital sound processing. Effective gain and speech perception. Arch Otolaryngol Head Neck Surg 127:1433-1437.

Snik AFM, Noten J, Cremers CWRJ. (2004) Gain and maximal output of two electromagnetic middle ear implants: are real ear measurements helpful? JAm Acad Audiol 15:249-257.

Snik AFM, Mylanus EAM, Cremers CWRJ, Dillier N, Fisch U, Gnadeberg D, Lenarz T, Mazolli M, Babighian G, Uziel AS, Cooper HR, O'Connor AF, Fraysse B, Charachon R, Shehata-Dieler WE. (2001) Multicenter audiometric results with the Vibrant Soundbridge, a semi-implantable hearing device for sensorineural hearing impairment. Otolaryngol Clin North Am 34:373-388.

Sterkers O, Boucarra D, Labassi S, Bebear JP, Dubreuil C, Frachet B, Fraysse B, Lavieille JP, Magnan J, Martin C, Truy E, Uziel A, Vaneecloo FM. (2003) A middle ear implant, the Symphonix Vibrant Soundbridge: retrospective study of the first 125 patients implanted in France. Otol Neurotol 24:427-436.

Todt I, Seidl RO, Gross M, Ernst A. (2002) Comparison of different Vibrant Soundbridge audioprocessors with conventional hearing aids. Otol Neurotol 23:669-673. 